\title{
Conclusions on Postdigital Futures
}

\section{When Biological Environments Change, Social Arrangements Need to Alter Too}

Seven years before Covid-19 became a reality across the globe, Dingwall, Hoffman and Staniland (2013) called for a Sociology of Pandemics. They argued:

Infectious disease has re-emerged as a public health threat in an increasingly globalised era, adding transnational actors to traditional national and local government actors. (Dingwall, Hoffman \& Staniland, 2013)

With a background in Sociology, I am not likely to disagree with applying critical theory to theorise pandemics (particularly when the year in which this book has been written has revealed just what global, local and individual reach a virus like Covid-19 has). Sociology can enable deep insights into social behaviour and society. It supports debate on complex relationships, power structures, social interaction and the language and culture that surrounds our everyday lives. Via empirical investigation and critical analysis, Sociology is a discipline that contributes to a body of knowledge about social order and social change, such as effects from the mandatory wearing of face masks, or shopping alone (Figure 50). Yet Sociology cannot tackle an analysis of the new postdigital positionalities we now find ourselves in on its own. In our rapidly changing postdigital context, interdisciplinary consortiums, cross-sector cooperation, analysis and interpretations are needed in order to capture powerful narratives across traditional, emerging and converging disciplinary shifts, amid rapid digital change.

In universities we have at our fingertips a wealth of academic disciplines, with new ones arriving regularly, alongside the social, scientific and technological changes that bring them into being. The pandemic has made our society 'anthropologically strange' to us (Dingwall, Hoffman, \& Staniland, 2013) and it has accelerated many technological and scientific changes that were already bringing fundamental shifts to how we might perceive ourselves as humans (Hall, 2013, Fuller \& Jandrić, 2018, Braidotti, 2019a, 2019b, De Vos, 2020, Savin-Baden, 2021). From simply spending much more time conducting activities online, right through to far reaching bioinformational and biodigital changes that are yielding new postdigital knowledge ecologies (Peters, Jandrić 


\section{You must shop alone} and face masks are mandatory

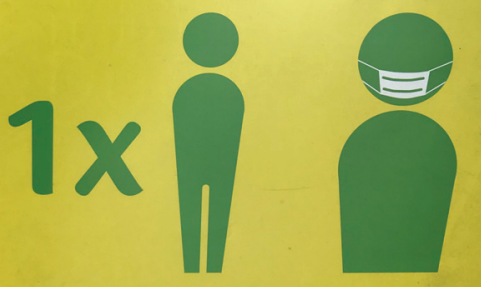

Government regulations require you to wear a face mask over your nose and mouth whilst in store, unless medically exempt.

You must shop alone, unless with a carer or child.

Please be kind and support our colleagues.

FIGURE 50

A reminder of government regulations during the pandemic

\& Hayes, 2021a), what we currently perceive as 'inclusivity' policy necessitates ongoing, interdisciplinary debate. In turn, universities and the regions around them, require new pathways for more dynamic postdigital policies, that are informed and updated organically through cross-sector dialogue and diverse positionalities.

Positionality has traditionally involved a reflexive dialogue between self, and the social and political context that creates individual identity, in terms of e.g. race, class, gender, sexuality, ability, status (England, 1994, Bourke, 2014, Luttrell, 2019). Positionality now needs to reflexively encompass too, the multiple reconfigurations between technologies and humans that alter who, and what, humans are. In their reconfigured status, human identities converge with effects from widespread digitalisation (OECD, 2O2O) raising new challenges in terms of equality, diversity and inclusivity agendas. Who, or what, contributes to discrimination, and who, or what, becomes a victim of bias, are new ethical questions to anticipate and debate. Then there are questions of whose logic influences related strategies and regulations and how this shift may now begin to alter the structure and values underpinning McPolicy discourse. 
In $\mathrm{HE}$ we have been required to distance ourselves from many structures we had come to accept due to Covid-19 and these measures have intermingled with the wider restrictions placed on our lives. Such fundamental alterations indicate that our 'social arrangements can, and must, change when biological environments change' (Dingwall et al., 2013). There is a recognition then in this acknowledgement of much wider infrastructures where dialogue between different forms of governance (technological, material, scientific, public health, economic, security, surveillance, media and communications, to name just a few) needs to aid a more critically sustainable response (Delanty, 2020). Berlant argues that 'infrastructure is not identical to system or structure' (Berlant, 2016: 393). Indeed, narrow calculative structures restrict what is knowable and thinkable in complex patterns of human interaction (Hayes, 2020). A 'glitch' like Covid-19 renders these structures visible for what they always were: not a reflection of infrastructure, just one form of structural organisation (Hayes, 202O). As such, $\mathrm{HE}$ requires new 'thinking infrastructures' that reflect the living mediation of what now organises life and learning, to help us to redo and rework previously restrictive policy models (Kornberger et al., 2019).

I argued in The Labour of Words in HE that it was time for humans to reoccupy the restricting McPolicy discourse we have worked within, but which has failed to linguistically acknowledge our academic labour (Hayes, 2019a). With no room for debate, McPolicy has provided a powerful structure to legitimate a series of measuring exercises of what activities might be enhanced across $\mathrm{HE}$. Yet still inequities persist, as intersections where policies need to meet are overlooked (Czerniewicz \& Rother, 2018, Hayes, 2019: 135, Equality Act Review, $202 \mathrm{ob}$ ). This is but one structuring of policy that emerged as an exercise of control to support the neoliberal, McDonaldised organisation of our universities. Based on a notion of a student as a passive consumer with a generalised experience that might be 'measured', this is a structure that now sits uncomfortably with new collaborative global sustainability goals and the ecological and positional approaches needed to support these. Furthermore, as universities prepare to admit a new generation of young people, already being referred to as 'generation Covid' (Wonkhe, 2021) who have lived with the disadvantages and mental health challenges of a pandemic (ImpactEd, 2021), it is necessary to review the issues that taking a simple therapeutic approach exacerbates (Apperley, 2014, Furedi, 2016, Ecclestone \& Hayes, 2019) and to respond to feedback from students on their online learning experiences (Jackson, 2021) to learn from this, beyond the pandemic. New values require new policies, and it is time to consider what policy shaped by postdigital dialogue (Jandrić et al., 2018) might offer us in terms of inclusion of diverse positionalities to address inequalities. 
I opened this book then with an intention to explore positionality in these postdigital times by raising a twofold debate. This has explored firstly, the new postdigital context that HE now occupies in society. This was examined in a year where a global pandemic has illuminated human digital dependencies and digital exclusion alike, out in the virtual airing cupboard of the Internet. Multiple and diverse 'actors' that are not all human, not all computer, are now shifting what, just a few years ago, were upheld as 'established' inclusive practices in universities (Department for Education, 2017). Therefore, I suggested secondly, that we might both recognise and explore what these rapid postdigital changes alter in our interpersonal relations and take a broader more inclusive view through positionality theory, on what strategies need to change in postdigital universities.

In our current approach towards equality, diversity and inclusivity agendas the focus has remained heavily tipped towards human interaction alone, with other non-human or beyond-human factors barely discussed, despite the powerful ways in which these now intersect across peoples' lives. Some have suggested that the pandemic has opened a portal through which humans might pivot from unsustainable levels of consumption. Others are arguing that we must 'build back fairer' (Health Foundation, 2020). As we look towards bioeconomic solutions and possibilities, complex questions of 'digital health' (Petersen, 2018) and 'human dignity' (Zwijnenberg, 2014) join a fundamental challenge raised at the start. This concerns how universities might link the disengaged forces of cultural reproduction and technological production (Delanty, 2001: 157). A convergence is happening now though that needs to be recognised in HE policy. Even the application of critical theory by humans to analyse the world around them looks set to shift, as critical theory itself may find it occupies a new or different positionality, as a result of a widespread digitalisation of biology (OECD, 2O2O).

\subsection{What Are We Airing and What Remains in the Cupboard?}

When I introduced my airing cupboard as a participant it was a tongue-incheek, playful analogy intended to draw attention to the intermingled 'airing' of so much information and human emotion across the Internet. Amid the broad dimensions of cancel culture there are complex rationalities at play, where even an author of a book on cancel culture itself, Julie Burchill, found herself cancelled by her publisher due to remarks she made over Twitter (ввС Entertainment \& Arts, 2020). Regardless even of the politics of this particular debate, it is perhaps interesting to note how this gets categorised under the 'entertainment' section of the ввс News website. Mark Carrigan has drawn attention to both the promise of social media in academia and also some deeply 
problematic strands we need to notice and be personally aware of. Drawing on the way in which platforms are designed to subtly encourage our compulsive use of them, this brings a theoretical background of behaviourism into people's everyday lives, homes and families. Therefore, whilst the 'mass character of commercial social media platforms breaks down the stable boundaries between the university and wider society, opening up a liminal space in which new ways of working can thrive', unfortunately there is a new 'professionalisation of Twitter within UK universities' which 'progressively undercuts this':

Its use becomes something which intersects with the institutional context in deeply obscure and rapidly evolving ways. I worry it has come to be something which hybridises the personal and the professional in the most subtly violent manner, leading work to become life and life to become work. (Carrigan, 2020b)

This is a topic picked up by Aral (2020) in a book: The hype machine: How social media disrupts our elections, our economy, and our health - and how we must adapt, who claims the pandemic ignited the online world like 'a digital forest fire' (Aral, 2020). Providing both 'human connectivity, social support and lifesaving information' but also acting as 'a cauldron of misinformation about impending national lockdowns and false cures', Aral argues that 'the threat of surveillance capitalism morphed into lifesaving disease surveillance' (Aral, 2020: xiv). Then there are the problems of a lack of legislation that will help to capture activities of hateful extremism across social media platforms, including hate crime, terrorism and incitement of violence. In a report: Operating with impunity: legal review (Commission for Countering Extremism, 2021) the balance between dangerous extremist activity and freedom of expression is confronted, with a call for a new legal framework to protect democracy.

\subsection{How Will HE Inclusivity Policy Include the Internet of Things?}

As discussed already, we are living currently with the irrationalities of our McDonaldised rational society and maybe a sense of the ridiculous can also help, as we seek to imagine possible alternative, postdigital futures. Static though it may appear then, there seem to be few barriers to me now inviting my hot water tank (just like other material or organic items) to become digitally intelligent and add its input to this debate. As part of the algorithmic internet of things (AIoT), the contents of my airing cupboard might join 'a paradigm shift where anything and everything can become interconnected', adding new security and privacy issues to existing ethical challenges (Pal, Hitchens, Rabehaja \& Mukhopadhyay, 2020). It then becomes necessary to question 
what reforms are needed to inclusivity policies (that still centre mostly around human-to-human discriminatory practices). Inclusivity policies themselves need to be inclusive of the hybrid assemblage of devices and potential data bias that humans now intimately interconnect with.

The connectivity that has made it possible to link up all manner of appliances, devices and objects through the Internet of Things (IoT) permits the territories of cultural reproduction and technological reproduction to become deeply interconnected across the virtual airing cupboard of the Internet. We are using the same complex virtual space to rant our hearts out across social media in one form of dialogue, and simultaneously we are conducting dialogue with doorbells, heating, appliances and the water tank in the hallway airing cupboard. All of this capability for gathering big data has arrived with us so recently that we are unable to conclude its fuller meaning. It is important that we try though, or as Thomas Ramge (2020) puts it, "how can human beings use artificial intelligence, intelligently?'

\subsection{Internet or Splinternet?}

Yet, even whilst contemplating such challenges, there are suggestions that cracks are appearing in the virtual airing cupboard of the Internet:

Over the last year, the worldwide web has started to look less worldwide. (Iyengar, 2021)

This claim is partly based on a series of potential bans of tech companies such as TikTok, WeChat and Twitter by various countries. It is also linked to a Facebook clash with the Australian government 'over a proposed law that would require it to pay publishers. Facebook 'briefly decided to prevent users from sharing news links in the country in response to the law, with the potential to drastically change how its platform functions from one country to the next' (Iyengar, 2021). Whilst a deal was reached to resolve this particular example, Facebook has suggested similar clashes are on the cards for the future. There is the concern that if:

territorial agreements become more common, the globally connected internet we know will become more like what some have dubbed the 'splinternet' or a collection of different internets whose limits are determined by national or regional borders. (Iyengar, 2021)

Such potential regulatory crackdowns around the world are attributed to a combination of rising nationalism, trade disputes and concerns about the 
market dominance of certain global tech companies. The major problem that arises however is that this is not just a process of 'upending the tech companies that built massive businesses on the promise of a global internet' as discussed by James Ball (2020). This is a situation that now threatens 'the very idea of building platforms that can be accessed and used the same way by anyone anywhere in the world' (Iyengar, 2021).

\subsection{Fragmentation or Sustainability and Inclusion?}

This potential fragmentation of the Internet adds a further layer of complexity to the arguments I have put forward for university policies for inclusivity to also be inclusive of all aspects of the postdigital contexts we occupy. If the Internet is now meeting persistent barriers from different laws in different nations, then this presents a major global challenge to both inclusivity and sustainability. Yet on the other hand, reining in the big tech companies is something that many countries around the world are now gaining confidence to do. As Iyengar (2021) points out, these 'companies are ultimately dependent on continued access to billions of users around the world, and governments have shown they are willing to cut off that access in the name of protecting their citizens and sovereignty online' (Iyengar, 2021).

As possibilities for developing new synthetic forms of life, organic memory and algorithmic medicines become realities in this context, we might question also the implications for how we understand 'digital health' (Petersen, 2018). As we contemplate these challenges to traditional understandings of the human body, there are legal, practical, methodological and ethical questions that cluster, not to mention those concerning research funding bodies and policy. Further convergence between digital and biological science is rapidly following and we are still grappling with how best to regulate algorithmic capabilities. This has left little time to discuss how to reconnect the 'old pipes' of HE (such as our theories, practices, processes and policies) with these new digital and biological wires, amid rapid, cross-sector societal change. These examples are reminders of the 'plumbing' we now need to undertake, if we are to address societal inequalities via new technological possibilities.

Reforms to inclusivity policies focused on human-to-human discriminatory practices alone, need to now be more inclusive of all kinds of hybrid reshaped humans and computers. The Humanities and Computing disciplines need to step up their dialogue too, but as an inclusive cross-sector, cross-disciplinary, exchange. Our HE policy making processes and discourse now require a more ecological basis of critical sustainability (Delanty, 2020) through which we might organically anticipate new forms of bias, accountabilities and possibilities, that these intimate encounters will bring. 


\subsection{Reviewing What Is Meant by Equality}

The Covid-19 pandemic has thus brought to light complex intersections where human biology and digital technologies intersect with human rights, data, environment and fluid aspects of personal identity and positionality. The postdigital nature of these interactions is revealed in the dialectics between human behaviour, such as social distancing, isolation, use of hand sanitiser and wearing of face coverings, alongside other technological and scientific innovations aimed at conquering the virus, as well as the use of data to inform decisions on when to lift lockdown restrictions. These aspects have interspersed with language too, as the mantras of 'hands, face, space' (Figure 51) and 'stay alert, control the virus, save lives' (Figure 52 ) have become adopted in physical places as well as online.

Ramge argues that 'artificial intelligence will not be able to relieve us of the burden of thinking, nor will it be able to tell us the right way to act socially' (Ramge, 2020). This means that we need approaches towards policy that can speak to both the diversity of people's positionalities and the rapidly changing postdigital contexts they find themselves in.

Objective forms of rationality, as revealed in McPolicy, are not likely to be able to address the linkages we require in universities between the disengaged

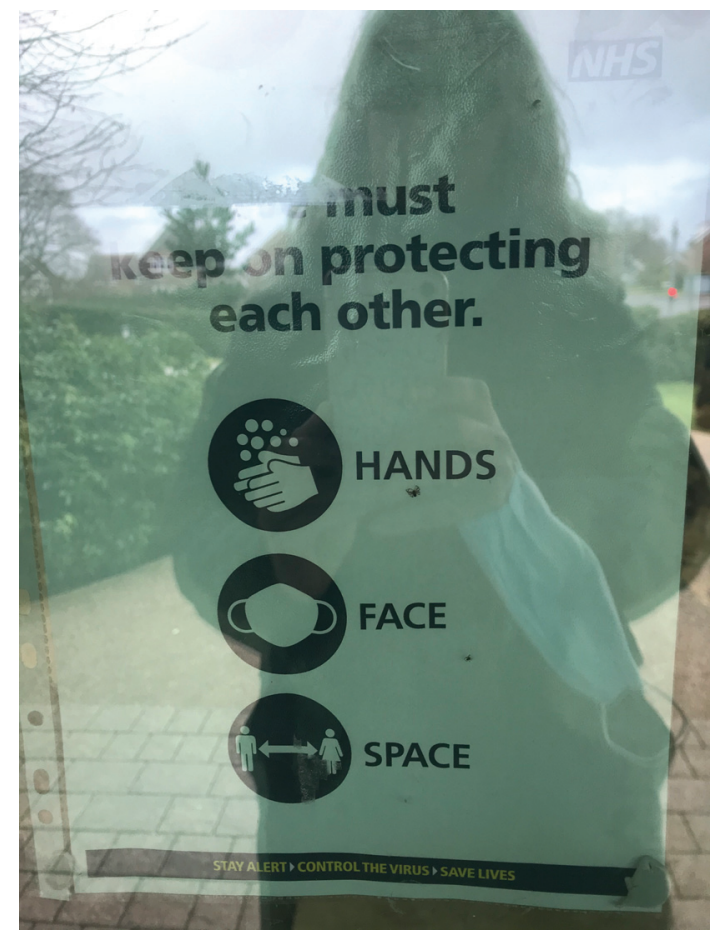

FIGURE 51

Reminders of the 'hands, face, space' hygiene routine 


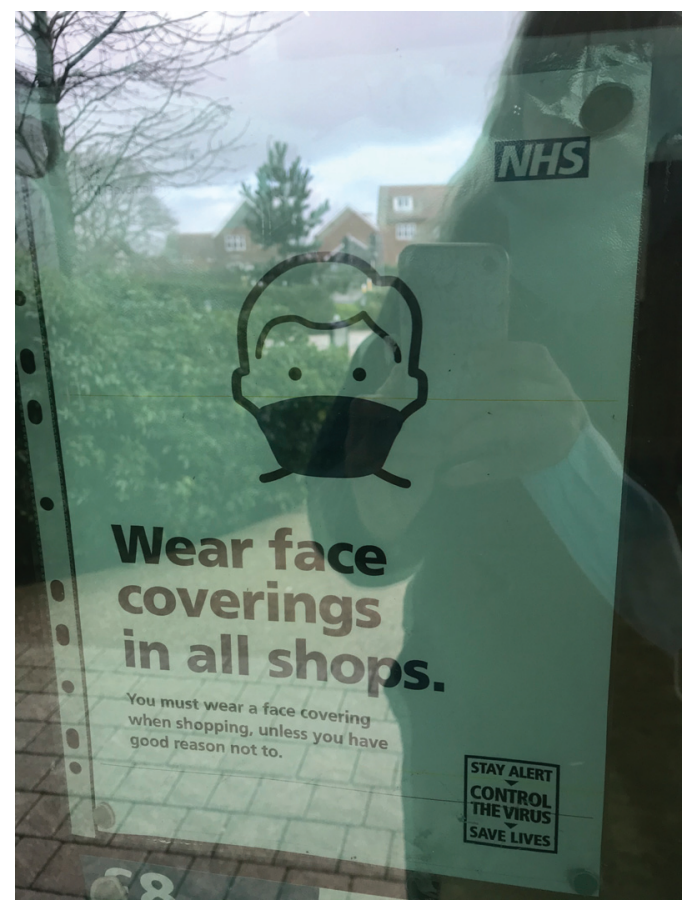

FIGURE $5^{2}$

Reminders of the requirement to wear face coverings in all shops

forces of cultural reproduction and technological production (Delanty, 2001: 157). Many examples of why this is the case have already been cited throughout the book but are also apparent in a recent review of the Equality Act 2010. In a campaign to review the Equality Act (Equality Act Review, 2020b) the convergence of multiple issues begins to be addressed in a suggested move away from a discrete list of protected characteristics alone.

An urgency to address poverty, unemployment, and inaccessibility to social and cultural capital exacerbated by the pandemic is being voiced in many related studies and reports.

\subsection{What Disadvantages Didn't Covid-19 Intersect With?}

On this basis we might wonder at whether there are any disadvantages that Covid-19 has not intersected with. Amid the conclusions in the Predicting Futures 2.o report (Equality Act Review, 2020b) that the handling of predicted grades algorithmically amidst the Covid-19 pandemic has widened the inequality gap and will continue to do so, there is a reference to a 'toxic intersection'. This is an adaptable notion concerning the point at which numerous disadvantages cluster together to compound existing inequalities for individual citizens. As many research studies follow the effects from the pandemic it is not difficult to demonstrate why 'the role of education as a vehicle for social 
mobility' is currently not working. In examples where there are low household incomes, there may also be challenges arising for different racial and ethnic identities. There may be additional influences too concerning the socioeconomic background people come from, or in relation to their gender. Then there is the largely unresolved gender pay gap that is widespread across all industries' along with the 'unconventional marker within intersectionality theory' of religion (Equality Act Review, 202ob). To add to these and many more characteristics that can merge in an individual's life to affect their positionality, education and employment opportunities, are the complex technological examples this book has discussed.

Yet technology alone cannot fix the challenges of equality and inclusivity in education either. As Reich puts it, technology is only as strong as the community of educators around it (Reich, 2020). Technology is frequently omitted in any depth from policies or reports on inclusivity, but Covid-19 has clearly shown us why the 'dialectics of digitalisation' (Ramge, 2020) with biological and cultural change can no longer be sat on the sidelines of this debate. Indeed, this is an inclusive topic in itself that each of us has a stake in.

\subsection{Digitalisation, Positionality and (Inter) Subjectivity}

De Vos (2020) argues that our very (inter) subjectivity is at stake now. Pointing to the way in which psychological interpretations about a problematic use of our data are often made at the point when there is some kind of breach, or bias, De Vos reminds us that it is psychology that actually underpins the platforms we use across the Internet. Digital platforms like Google, Facebook, Twitter and others 'function fundamentally via heuristics that are informed by psychology' (De Vos, 2020). Silicon Vally companies have a principal interest in knowing our searches, clicks and likes and so in other words, our desires. Given how much we share, they know the dirty laundry we each air too. Or as DeVos puts it 'our thoughts, images, emotions, memories' present themselves in this 'amphitheatre for our psychological life'. As such, De Vos recommends that psychologists need to proceed critically with regard to digitalisation and to disentangle their (neuro) psy-theories from their implications given that these actually structure the digital technologies themselves that are under scrutiny.

Here then we have a matter of positionality for the researchers in psychology to reflexively address. Still though it is one that involves us all when DeVos poses the question that: 'if psychoanalysis constitutes the most expedient critique of how the psychoanalytic infrastructure of digitality is compliant with, and even fundamental to, what one might designate as digital capitalism, then could psychoanalysis also offer an alternative for a different mode of 
digitality?' It is an important question to pose, and also to raise it from many different disciplinary angles, when we contemplate the place that data intensive biology appears to be taking up now in education.

\subsection{Data intensive Biology in Education}

Whilst the digital may have become 'the master narrative of our world' (Fuller \& Jandrić, 2019: 215), the biological is more important than ever (Mañero, 2020). Ben Williamson has drawn attention to how advanced technologies that can process complex biological data have now transformed the human sciences and are now being used to conduct studies and generate new knowledge in the field of education (Williamson, 2019a). Pickerskill (2020) has demonstrated how epigenetic processes are of increasing interest to a range of professionals beyond biomedicine. This he says is piqued by the notion of 'the plastic body' and 'the belief that bioscientific research is demonstrating new molecular mechanisms through which the social and physical environment impact upon the bodies of humans and other animals' (Pickerskill, 2020: 72). These are far reaching interventions that extend the idea of what education is and what it can do. The problem lies in what rationality sits behind the interpretations that are being made, such as visions of biology that ahere to certain ideas of a 'good society' and the policies and practices need to reach this (Pickerskill, 2020: 79). Citing some 'problematic ontological moves from specific behaviours in rats to assemblages of actions and ideas in humans when theorising about the import of epigenetics for education', Pickerskill uncovers some worrying pathways. He suggests therefore that:

If biological and education researchers are going to be increasingly wading into each other's waters, substantive, thoughtful, and self-critical dialogue between them is surely warranted. (Pickerskill, 2020: 72)

Williamson has adopted a categorisation of 'precision education' for these and other developments such as brain-based teaching (Pykett, 2015), neurotechnologies and polygenic scoring (Williamson, 2019a) and argues for the necessity of interdisciplinary collaborative research across areas such as education technology and governance, social and political geography and sociology of science and medicine.

\subsection{What Visions May Lie Ahead in a Bioeconomic Political Economy?}

Taking into account these, and indeed all of the digital challenges and possibilities that have been 'aired' in this book to aid the debate on postdigital positionality and inclusivity in $\mathrm{HE}$, I will turn finally to reflect on what a 
bioeconomic political economy might offer not only as an alternative to our current neoliberal political economy, but in changing the McPolicy discourse. Delanty (2020) discussed the notion of critical sustainability and a postcorporate HE. In a series of recent papers Michael Petars, Petar Jandrić and I have recently explored ideas on what biodigital philosophy and technological convergence might yield in terms of new and powerful knowledge ecologies (2021a). In a follow up paper, we then discussed biodigital technologies and the bioeconomy in relation to the global new green deal (2021b) and in a third paper, we embarked on a postdigital-biodigital debate to raise varied questions that had been occurring to each of us in writing the previous two papers (2021c). In a fourth paper (2021d), we revisited the concept of the 'edited collection' itself, to explore new values and approaches that might emerge in collaboration with other authors on the Bioinformation Philosophy and Postdigital Knowledge Ecologies book (forthcoming). Our work on these papers has helped to consolidate our positionalities on many interesting questions and ideas, but there are many more questions ahead for us all.

Currently there are far reaching consequences for our environment and ourselves if a change of direction from our current political economy is not realised. Now that technological and scientific progress towards a circular bioeconomy presents possible solutions, there are questions that the social sciences and humanities need to raise, alongside new educational programmes to help effect far reaching and critically sustainable change (Saachi, Lotti and Branduardi, 2020). Therefore, for me and my interest in altering the tired McPolicy discourse in HE, I have wondered whether 'political bioeconomy' represents a new, extended field of thought, or an alternative way that society is organised. What new discourses and related behaviours might emerge then through political bioeconomy? Might we witness a change of direction from the dominant, growth focused, market-led discourse about how technology will automatically enhance experience (as if experience were something universal that we all share)? If new forms of 'political bioeconomic discourse' are on the horizon for us, then such a discourse would contribute to new directions for the postdigital debate that I have proposed on inclusivity. It leaves me wondering too, what kinds of reasoning powers will we be likely to require for our debate in a political bioeconomy? (Peters, Jandrić \& Hayes, 2021c).

\subsection{What Might a Political Bioeconomic Discourse Look Like in HE Policy?}

Thirty years ago Hlynka and Belland (1991: v) argued that whilst the paradigm shift identified by Thomas Kuhn (1962/2012) drew attention to alternative methods of research, it is 'ironic that educational technology, a field which 
prides itself on being within the vanguard of change, suddenly appears instead to be lagging behind other fields and disciplines'. They added that 'educational technology appears to have become stuck fast in a technological means-end model' (Hlynka \& Belland, 1991: v). In the disappointing decades that have followed, this quick-fix identity for technology within education has been overlaid and repeated in the policy discourse that has accompanied many years of digital development. Furthermore, it left us ill-prepared to meet individual learners at their point of need during successive lockdowns, as widespread digital poverty and exclusion has been revealed (Holmes \& Burgess, 2020, Westwater, 2021). The 'coronavirus pandemic has injected fresh urgency into the education technology conversation' and 'it is important to note that there is no "one size fits all" solution to modernising education; it will very much depend on individual courses or student needs' (Li, 2021).

If a political bioeconomic discourse is to offer a more ecological and inclusive alternative to McPolicy in $\mathrm{HE}$, then it will require critical understandings to develop across education, government agencies and commercial providers to finally shift from a widely critiqued 'student-as-consumer' approach (Driscoll \& Wicks, 1998, Molesworth, Nixon \& Scullion, 2009, Bunce, Baird \& Jones, 2017, Brooks, 2018, Peters, Jandrić \& Hayes, 2018, Hayes and Jandrić, 2018: 128, Hayes, 2019a). A consumer model of student learning derived from our neoliberal political economy (Olssen \& Peters, 2005) and a McDonaldisation of $\mathrm{HE}$ (Hayes, D, 2017) reflected in a discourse of McPolicy (Hayes, 2019a) will no longer align with the aspirations of a resilient, sustainable bioeconomy (Peters, Jandrić \& Hayes, 2021b). Therefore, HE policy needs a new relationship with the postdigital environment that universities now occupy. This includes an analysis of evolving new working patterns during lockdown that can be observed to some extent even via examining electricity usage (National Grid, 2020). Then there are the benefits and risks involved in home working, including additional 'vulnerability to cyber crime' through the Internet that has arisen for many during the pandemic. In a report entitled: The UK's Response to Cyber Fraud A Strategic Vision a response that goes beyond the incremental change that has occurred over the past few years' is called for. This is because 'cyber fraud now accounts for most of the fraud committed in the UK' (Dawda, Janjeva \& Moiseienko, 2021). The authors argue too that it poses distinct challenges compared to 'traditional', offline types of fraud, such as:

A need for high-quality digital forensic skills in the investigation of cyber fraud; the virtually unlimited pool of possible offenders from around the world; and the likelihood that - in contrast to the investigation of other 
types of crime - state-of-the-art expertise and resources may reside in the private sector rather than law enforcement agencies. (Dawda, Janjeva \& Moiseienko, 2021)

Whilst Gary Hall (2013) argued that the digital humanities does not bring computing and humanities together as 'equivalent', digitisation has extended such a reach across disciplines, life and work that Braidotti (2019a) has called for a theoretical framework for the critical posthumanities to incorporate new fields of transdisciplinary knowledge. Her work also brings new insights for how a so-called non-human might be suitably acknowledged alongside a human. As I have argued throughout this book, all humans and non-humans need to be given their place as participants in inclusivity strategies. This emphasises also that rather than reduce the role of the humanities, arts and literature in universities, as recent developments have indicated, a new emphasis might be drawn on why literary communities actually 'matter to human rights' (Stonebridge, 2020). This links well with postdigital understandings and Delanty's arguments for a critical sustainability discourse that might move us forward in a post-corporate model for $\mathrm{HE}$.

To appreciate how a widespread digitalisation across all aspects of life in the virtual airing cupboard has shifted positionality, we might reflect once more on Braidotti's argument that in our online activities we are increasingly required to verify that we are in fact a human, and not a robot of some sort (Braidotti, 2019a). To this example we might add many other instances where a constant and fatiguing verification of our human identity and permissions is required in the virtual airing cupboard. We make repeated 'sign ins' that require complex passwords to be updated, an acceptance of cookies is expected from us at every turn. Autocorrect does its utmost to cause embarrassment whenever we send a text hastily and don't look to see what has been altered. Then there are the unexpected reminders we may never recall requesting, such as details of our daily or weekly screen time flashing up before us, or the latest news stream popping up alongside many inconvenient system updates which provoke automatic computer shutdowns. This situation 'assumes as the central point of reference the algorithmic culture of computational networks - not the human' (Braidotti, 2019a), but we are rapidly moving towards a more ambiguous situation still, where digital processing of complex biological data has now started to alter disciplinary focus in the sciences (OECD, 2O2O) and to bring 'precision education' into universities (Williamson, 2019a). Such advances are yielding new postdigital knowledge ecologies (Peters, Jandrić \& Hayes, 2021a) and an urgent need for these developments to be reflected in new forms of HE policy for inclusivity. 


\subsection{Giving the Final Word to the Airing Cupboards, Silos, Apps and Climate Change}

Whilst people can take to the streets (when not in a pandemic lockdown) and protest for greater equality and acceptance of diversity, when they take to the 'sheets' within the virtual airing cupboard, they may find that their human liberty and positionality is continually overridden. Not only is it pretty 'heated' out there in the virtual airing cupboard of the Internet, through cancel culture between people, our data and verbal exchanges travel through many more 'collaborators' than we can see or possibly know.

It is a state that has become normalised, but it alters how human rights, diversity and inclusivity are enacted. Amoore (2020) raised the problem that 'machine learning algorithms that anticipate our future propensities are seriously threatening the chances that we have to make possible alternative political futures' (Amoore, 2020: 1). Braidotti (2019b: 31) therefore questions: 'what are the parameters that define a posthuman knowing subject, her scientific credibility and ethical accountability?' She refers to 'posthuman times', which is a matter for critical debate in itself, when there are others who would argue that 'we have always been posthuman' (Matthewman, 2011: 172). Setting this debate in a postdigital context is just one way to acknowledge a landscape of global, cross-sector, biodigital and disciplinary change, along with the complexities that this brings to individual positionalities.

Price (2O2O) has put forward the case for examining 'human-virus-data relations' and issues of social justice that arise as governments have come to rely on contact tracing apps to help address the global public health emergency (Price, 2020: 772). This provides another route into looking at forms of postdigital hybrid assemblages that Covid-19 is illuminating and the impact these have on people's individual postdigital positionalities. The apps collect data via people's smart phones for analysis by a risk-scoring algorithm to determine if public health authorities should be alerted if a user has come into contact with a person with Covid-19. The apps may be a tool, but they are more than this, they are 'biological-more-than-human-entities'. Given that use of contacttracing apps is mandatory in certain countries and some groups in society may be stigmatised or disenfranchised by contact-tracing apps. Contact-tracing apps 'may increase the vulnerability of those who are already vulnerable, reduce and weaken data security and privacy, and undermine trust in healthcare provision' (Price, 2020: 787). Placing these arguments within our broader, global environmental challenges, and the multispecies entanglements that are needed to sustain life on Earth, Price argues that humans are just as likely to exploit them and that: 
Covid-19 most likely arose because of the human exploitation of another species. Only when we acknowledge these contradictions, can we move forward in addressing the problems we are collectively facing. Whilst it may not be immediately obvious what the relationship is between the Anthropocene and Covid-19, the two are inextricably linked. (Price, 2020: 776 )

Gergen (2009) puts forward the idea that we live in a world of 'co-constitution'. Suggesting that we are always already emerging from relationship, that we cannot step out of relationship and that even in our most private moments we are never alone. Gergen argues that for the wellbeing of the planet we must protect the 'generative processes of relating' (Gergen, 2009). With this idea in mind, postdigital positionality provides one way to examine how we might inclusively relate all aspects of our postdigital society to each of our diverse positionalities. Our environment has changed and, as we alter and adapt to new convergences and possibilities, the challenge is for HE policy to recognise the impact of these co-constituted matters in the lives of students and staff.

Our current political economy is predicated on consumer consumption rather than environmental renewal, but even the discourse of activism now needs to change. Indeed, as observed by the Venerable Dr Rosemarie Mallett, Archdeacon of Croydon, there is a distinct lack of diversity amongst climate activists. This is particularly apparent in this big year for environmental activism as preparations take place for the landmark COP26 conference to be held in Glasgow, UK in November 2021.

Mallett suggests that it is time to move beyond the merely disruptive 'shocking' protests, as this kind of action could be deemed to be a 'white middle-class activity', with black people more aware of the impact on their lives if they get arrested (Holland, 2021). Questioning whether the climate movement is now 'at a crossroads' she points out that 'change often doesn't come via revolution but via evolution' (Holland, 2021). It is therefore time for HE to take a leading role in such cross-sector and cross-societal evolutionary change. To begin to relate university policies for inclusivity to the wider environment of critical sustainability that has already accepted our more-than-human collaborators, is a good place to start. Thus, to conclude on a final point of wackiness, Scott (2010: 18) suggests that 'we need to better exploit and learn from the multiple natural experiments in institution building, maintenance, and demolition now underway in our rapidly changing world'. Having drawn on a few metaphors during the course of this book, as well as people's concerns over the 'behaviourist' stance that our digital technologies have emerged from, I may as well 


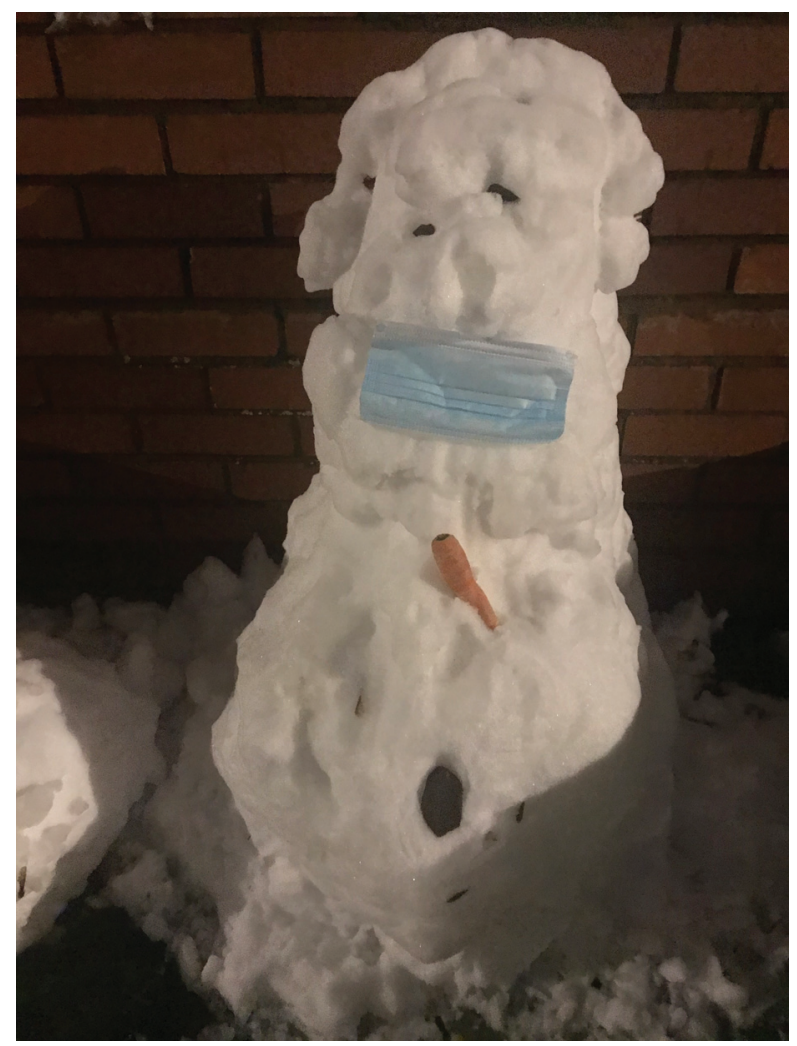

FIGURE 53

A snowman sports a face mask alongside the more traditional carrot during Winter 2020

return to these considerations. Given that a silo (we understand) is already engaged in 'constructive thinking', the question to bring to our next postdigital debate is, are we?

Even as I conclude this book, a university consortium is bringing together several ground-breaking threads of biodigital research to create the Active Living Infrastructure: Controlled Environment (ALICE). A prototype that could revolutionise housing and replace fossil fuels through 'living bricks', ALICE:

creates a living, breathing, energy-generating microbial system that can simultaneously supply power to your home and talk to you through augmented reality to tell you how productive and 'happy' it is. (UKRI, 2O21)

Price points out that we need to find ways to live alongside our apps and other 'more-than-human counterparts'. As such, we 'need to learn to stay with the trouble and not to be afraid to stand up to what we are unsure of' (Price, 2020: $789)$. 
Perhaps if we manage to bring the bricks, silos, contact tracing apps and airing cupboards on board with inclusive forms of 'critical thinking', as part of the intimate flow of knowledge passing between the humanities and computing, and critically and honestly represent these relationships in university policy discourse, then we may really begin to know where we stand. 